\title{
The Effect of Enterprise Crowdsourcing Systems on Employees' Innovative Behavior and Job Performance
}

\author{
Vetrivadivel Vel \\ Dakota State University \\ vavel@dsu.edu
}

\author{
Insu Park \\ Dakota State University \\ Insu.Park@dsu.edu
}

\author{
Jun Liu \\ Dakota State University \\ Jun.Liu@dsu.edu
}

\begin{abstract}
Employees are main sources of innovative ideas via their insights of companies' products, processes, customers, and competitors. Enterprise crowdsourcing systems (ECSs) are used to collect, refine, and realize ideas. However, only a small percent of employees submit ideas - about 7.7\% at Pfizer, 2\% at HCL Technologies, and 3\% at Polaris Industries. Why employee's participation is low? More specifically, what are the factors that can lead employees to use ECS actively to submit and share their innovative ideas for improving their job performance? In this research, we used a multi-actor dyadic survey to survey 183 employees and their managers and conducted data analysis to understand the impact of ECS factors on employees' job performance. The findings of this study can help organizations refine their ECSs and innovation initiatives.
\end{abstract}

\section{Introduction}

Innovation helps create new products, make improvements to existing products, and reduce expenses by improving operational efficiencies [23, 53]. Traditionally, innovative ideas come from consultants outside the organization or a specific set of employees within the organization such as its R\&D personnel [61]. Recently, with the development of Enterprise Crowdsourcing Systems (ECSs), all employees, not just R\&D personnel, can submit innovative ideas to online repositories using their computer's web browsers. Organizations can then evaluate and implement the ideas to increase their profit [62] and reward employees for their submission of ideas. ECSs are the information systems that are used by organizations to harness the skills, inputs, information and capabilities of all employees across all functional and hierarchical levels. With Web technologies, ECSs enable easy contribution and interaction that can help increase the number of innovative idea submissions. Many of the ideas will later be implemented, thus benefiting not only organizations with increased profits but also employees with recognition and rewards. For instance, Polaris, a leading motor vehicles manufacturer, introduced four new vehicle models and improved its R\&D process [23] by implementing innovative ideas submitted by its employees to the ECS. Similarly, HCL Technologies, a global IT services company, offered seed funding for their employees to submit and develop innovative ideas [56].

These enterprise crowdsourcing repositories, however, do not seem to be actively used by employees to submit innovative ideas, even though employees are usually rewarded for their ideas. For example, In Pfizer, only $7.7 \%$ of their 77,000 employees participated and submitted 650 ideas to Pfizer's ECS [23]. In HCL Technologies Limited, only $2 \%$ of their 200,000 employees [56] and in Polaris Industries, only $3 \%$ of their 7,000 employees submitted ideas to their ECSs [40]. This lack of employee participation prompted us to investigate the following research question: What are the ECS factors can lead employees to use ECSs actively to submit and share their innovative ideas to improve their job performance? Understanding these influencing factors will help organizations to improve their ECSs to attract more employees to participate in submitting and sharing innovative ideas. Since ECSs are nascent, there is no IS research exploring the role of ECS factors such as knowledge sharing and support in enabling employees' innovative behavior. In this research, we develop hypotheses that examine the effects of ECS factors on employees' innovative behavior from a knowledge management perspective (i.e., knowledge sharing and knowledge application) with moderating effects including knowledge application, ECS satisfaction, and innovative behavior.

\section{Literature review}

\subsection{Crowdsourcing and crowdsourcing systems}


Crowdsourcing typically means the common contribution of the interested people (crowd) who are part of non-hierarchical group to solve a common problem using their diversified knowledge [53]. Saxton et al. [50] defined crowdsourcing as "a sourcing model in which organizations use pre-dominantly advanced Internet technologies to harness the effort of a virtual crowd to perform specific organizational needs" (p. 5). The information systems that are used to harness the virtual crowd's effort are called crowdsourcing systems. Mainly, crowdsourcing systems are hosted in two ways - organization hosted and third-party provider hosted. In our research, we focus on organization hosted crowdsourcing systems, also known as enterprise crowdsourcing systems (ECSs), in which the crowd is all their employees across various domains with different background that will participate to solve organizational problems innovatively.

\subsection{ECS factors}

The uniqueness of ECSs compared to other information systems and E-Commerce is its ability to provide knowledge management features to acquire, share and apply knowledge. The primary features of ECSs include user management, contribution management, trust management, workflow management, and task management [28]. User management coordinates any required collaboration between employees. Collaboration can be improved by openness of all ideas - raw and being refined [55]. Contribution management allows employees to submit their ideas and other employees to view the submitted ideas to provide their comments, cast votes, select the best ideas, and also adapt them into their ideas and apply in their domain [41]. ECSs that are open to everyone can facilitate an internal culture of openness and cooperativeness, which has been considered a key attribute of organizations that have succeeded with employee driven innovation (EDI) [55] using idea submission portal/system capable of collecting, refining, and applying ideas [34]. Trust management ensures that right compensation, recognition, and credit go to the contributing employees. Employees expect fairness in receiving appropriate rewards for their creative contribution, and their intention to share knowledge depends on this [33]. Workflow management includes defining and managing workflows efficiently. Workflows coordinate inputs and outputs of humans and machine functions to get optimal result in a process [28]. An efficient workflow management is critical in ECSs as they are complex systems that require employees and enterprise systems' inputs.

\subsection{Knowledge sharing and creative knowledge application}

Knowledge sharing is the process of spreading organizationally relevant information, knowledge and skills across organizations [45]. Both tacit and explicit knowledge are shared across organizations using several tools including IS. It is important that the shared knowledge is used effectively to complete operational business processes. Using or integrating the shared knowledge in existing business processes is known as knowledge application [15]. Employees use their highly skilled tacit knowledge creatively to improve current business processes or products or to create new products, processes or ideas. Creativity in organizations is defined as generating novel ideas to improve or create processes, products or procedures [4]. For our study, we define creative knowledge application (CKA) as "an employee's behavior to finding new uses of existing ECS knowledge, workplace IS, and resources to support their job" based on trying to innovate using IT [1] and innovative IS use [42]. ECS is an effective tool for employees to share and apply tacit knowledge by congregating, collaborating, producing or improving new products, services, and processes [50]. People, processes, and tools are jointly responsible for innovation and development in organizations [58].

\subsection{Innovative behavior}

Innovation is the successful implementation of creative ideas [3]. Innovative behavior is performance or production (not adoption) from using novel ideas for conducting their job [52] by individuals or small groups of individuals working together [3]. In this study, innovative ideas can be novel ideas regarding a product or process submitted by employees to the innovation portal or existing ideas that are adopted and adapted to different contexts by other departments. ECSs have features to collect new ideas, announce challenges requesting new ideas, enable employees to comment and rate ideas, and allow employees to add additional information to submitted ideas and browse status of all ideas. They could build the metaknowledge and provide visibility to invisible knowledge to all employees including employees who are not directly involved in specific ideas [41]. This visibility can help increase collaboration among employees resulting in increased innovative behavior. 


\subsection{ECS satisfaction and job performance}

User satisfaction is an important criterion for measuring the success of IS. Though indirect, it is the most prevalent measure of IS success due to its applicability and ease of use [44]. Ives et al. [32] defined user satisfaction as the degree to which users believe that the IS at their disposal fulfills their needs. Au et al. [6] defined user satisfaction as the sum of experiences that user acquires from his/her interaction of technology over time, and it represents users' cognitive evaluation of the entire IS user experience. Adapting from definitions of user satisfaction and job satisfaction [43], we define ECS satisfaction as "a pleasurable or positive emotional state resulting from the appraisal of an ECS or experience using an ECS". Bhattacherjee [10], in expectation-confirmation framework, states that user satisfaction is resulted when expected benefits of information system use are confirmed or realized. Employees using ECSs can feel satisfied when they realize that shared knowledge in ECSs is applied and integrated into their work and organizational processes to improve efficiency as originally intended by ECSs.

We follow Viswesvaran and Ones's definition of job performance [60]. It is behavior and outcomes that employees engage in or bring about that are linked with and contribute to organizational goals. It includes factors such as productivity, work quality, improved job performance, and time save [21,39].The impact of IS on individual performance has been wellresearched. DeLone and McLean [20] state that user performance impact is a good sign that the given IS has provided the user a good knowledge of the decision context, has enhanced the user productivity, or has evolved his or her perception of the value or effectiveness of the IS [54].

\section{Hypotheses}

\subsection{ECS factors and creative knowledge application}

This study uses both knowledge sharing and knowledge application in studying employees' innovative behavior. Knowledge sharing is the process in which organizationally relevant information, knowledge, and expertise are spread and exchanged among employees within organization. The value of knowledge is realized when employees' highly tacit and subjective domain insights are tapped into and made available for sharing and applying across organization. Tacit knowledge is a tremendous source for innovation [45]. Moreover, when knowledge is used by employees, learning takes place, which could result in an improved pool of organizational knowledge [46]. Access and exposure to diverse knowledge will help employees improve opportunity recognition, enlighten new ways to solve problems, and nurture innovation activities [57]. Knowledge sharing can also increase the likelihood for combinations of existing and new knowledge to produce new products and improvements [30], thus protecting knowledge from expropriation. Based on this, we hypothesize that,

\section{H1: Employees' knowledge sharing behavior will increase their creative knowledge application.}

Employees use IS as a part of their daily work, and they become habitual users. This repeated use will increase their familiarity with the information systems. When employees believe that IS will help them solve and improve their work performance, they will increase its use[47]. When employees begin seeing that ECS has the capability to help them be creative, they will use it as a result of conscious attempts at improving habitual actions [17]. Employees will also identify creative uses of ECS features and functions due to their familiarity of ECS, which could result in applying knowledge to improve organizational products, services, processes etc. Based on this, we hypothesize that,

H2: Employees' belief of ECS Support for creative use will increase their creative knowledge application.

\subsection{The effect of creative knowledge application}

The benefits of technological innovations such as ECSs can be realized only when they are completely accepted and used [25]. According to DeLone and McLean's IS success model, the IS use results in user satisfaction [19]. Thus, IS satisfaction is increased as the result of effective IS use and is based on the willingness to repeatedly using existing systems [65]. Park et al. [47] offer two main reasons for employees using their information systems. First, employees continuously use when they are satisfied with their IS and perceive usefulness [10]. Employees also repeatedly use their ISs when they believe that it is a useful tool that will enhance their performance and is not a replacement of their work and skills.

Employees' satisfaction toward the ECS improves as they voluntarily use it [47] as the use of ECS is primarily optional and voluntary in comparison to operational IS [25]. User satisfaction arises when employees realize that shared knowledge in ECS is 
applied and integrated into their work and organizational processes to improve efficiency as originally intended by ECS. Based on this, we hypothesize that,

\section{H3: Creative knowledge application is positively} related to ECS satisfaction.

Idea realization culminates in behavior. Creative knowledge application may enable the integration of shared knowledge in developing new products and prototypes and also improve the existing products. Knowledge application is key for organizations to take full advantage of collective knowledge to achieve maximum performance [2]. Organizations exist because they can better integrate the specialized knowledge and protect knowledge from competitors [24]. Specifically, organizations and individuals that have proficiency in gathering and integrating knowledge are more likely to have the potential to sustain high levels of innovation. The openness of the ECS across organizations allows employees to effectively apply or adapt ideas submitted by others, either by collaborating with the submitter or by providing credits. Based on these, we hypothesize that,

H4: Creative knowledge application is positively related to innovative behavior.

\subsection{The ECS satisfaction on job performance}

DeLone and McLean [19] established that user satisfaction will result in net benefits for individuals and organizations. These net benefits include cost savings, expanded markets, incremental additional sales, reduced search costs, time saves, etc. The impact of user satisfaction on user performance has been well documented in literature. Guimares et al. [26] found end user satisfaction has significant relationship on end user job performance in server/client. Hou [29] found that user satisfaction has strong direct influence on users' performance in Business Intelligence systems context. Based on these, we hypothesize that,

H5: ECS satisfaction is positively related to job performance.

\subsection{The innovative behavior and job performance}

Organizations and employees collect and possess intelligence about their customers' needs and competitors' product lines [31]. Highly motivated innovative employees transform this intelligence into creative ideas in various forums including ECSs and develop new products and services, resulting in increased relative market share, relative sales, relative ROI, relative profitability, etc.

The goal for innovation in workplace is to bring high performance gains [5]. Individuals' innovative behavior resulted from companies' new technologies such as ECSs is expected to bring new ways of doing their job and bring about efficiency gains in terms of increased productivity, work quality, decreased error rate, increased ability. We hence hypothesize,

H6: Employees' innovative behavior is positively related to job performance.

\section{Proposed research method}

\subsection{Method}

We conducted a field study utilizing a multi-actor dyadic survey method [37] to avoid self-reported bias (common method bias) [36] [16]. The subjects were employees in organizations that utilize enterprise crowdsourcing systems to innovate. To avoid participation bias [61], the sample was randomly selected to include subjects that have used and notused ECS to submit innovative ideas. Data were collected online from employees of 15 information technology related companies in the U.S between September and November 2016. Followers $(\mathrm{N}=300)$ and their supervisors $(\mathrm{N}=92)$ were invited to complete surveys. We received usable data from 183 dyads (effective response rate of $61 \%$ ) who are familiar with their innovative behavior. The usable number of dyads is an acceptable size and consistent with similar studies [37] [51]. Specific data regarding the subjects' personal attributes, and their employers' support for innovation were also gathered.

Most measurement scales for this study were adapted from the existing measures used in prior studies that were proved reliable and valid. The surveys were initially pilot-tested and the feedbacks were incorporated into the formal surveys. Formal surveys were completely filled by 183 employees and 74 supervisors from different domains. There were 39 supervisors with 1 employee, 10 with 2 employees, 4 with 3 employees, and 2 with 6 employees responded. Table 1 provides the demographic characteristics for employees. 
Table 1: Des criptive $s$ tatis tics

\begin{tabular}{|ll|}
\hline Gender & $\frac{\text { Age }}{<21}$ years: 3 $(1.7 \%)$ \\
Fale: $98(53.6 \%)$ & $21-30$ years: $45(24.6 \%)$ \\
& $31-40$ years: $59(32.2 \%)$ \\
Job Title & $>40$ years: $76(41.5 \%)$ \\
Executive: $28(15.3 \%)$ & Job Experience \\
Manager: $92(50.2 \%)$ & $<1$ year: $8(4.5 \%)$ \\
Other: 63 $(34.5 \%)$ & $1-5$ years: $71(39 \%)$ \\
Education & $6-10$ years: $60(32.8 \%)$ \\
Doctorate: $7(3.8 \%)$ & $11-15$ years: $23(12.6 \%)$ \\
Prof. Degree: $53(29 \%)$ & $16-20$ years: $11(5.6 \%)$ \\
4 year degree: $74(40.4 \%)$ & $>20$ years: $10(5.5 \%)$ \\
2 year degree: $17(9.2 \%)$ & Submitted Ideas in \\
Some college: $19(10.3 \%)$ & $\underline{\text { ECS? }}$ \\
High school graduate: 15 & Yes $-142(77.6 \%)$ \\
(8.1\%) & No $-41(22.4 \%)$ \\
\hline
\end{tabular}

Table 2. Inte rco rre lation

\begin{tabular}{|l|c|c|c|c|c|c|c|c|c|}
\hline & $(1)$ & $(2)$ & $(3)$ & $(4)$ & $(5)$ & $(6)$ & $(7)$ & $(8)$ & $(9)$ \\
\hline (1) Job Perf & 1.000 & & & & & & & & \\
\hline (2) ECS Sat & 0.826 & 1.000 & & & & & & & \\
\hline (3) Innovation & 0.307 & 0.149 & 1.000 & & & & & & \\
\hline (4) KAP & 0.787 & 0.923 & 0.190 & 1.000 & & & & & \\
\hline (5) KS & 0.752 & 0.900 & 0.172 & 0.949 & 1.000 & & & & \\
\hline (6) Suppoort & 0.783 & 0.935 & 0.169 & 0.922 & 0.924 & 1.000 & & & \\
\hline (7) Age & -0.135 & -0.182 & -0.010 & -0.187 & -0.167 & -0.187 & 1.000 & & \\
\hline (8) Education & -0.235 & -0.250 & 0.029 & -0.223 & -0.216 & -0.221 & 0.061 & 1.000 & \\
\hline (9) Experience & 0.069 & -0.013 & -0.005 & -0.033 & -0.040 & -0.031 & 0.403 & -0.035 & 1.000 \\
\hline (10) Gender & 0.239 & 0.235 & -0.138 & 0.245 & 0.191 & -0.238 & -0.085 & -0.321 & -0.011 \\
\hline
\end{tabular}

\subsection{Measures}

4.2.1. Knowledge sharing. Knowledge sharing is measured using six-items scale adapted from [38]. Sample items included, "I eagerly reply to innovative ideas posted by other employees in ECS" and "I often help my fellow employees ECS who seek support from other members".

4.2.2. Belief of ECS' support for creative use. This construct is measured using ten-items scale, which were from creative behaviors measured by [64]. Sample items included, "I take active part in submitting ideas in innovation portal" and "I eagerly reply to postings seeking help in ideas in innovation portal".

4.2.3. Creative knowledge application. Creative knowledge applications is measured using five-items scale adapted from [15, 12]. Sample items included, "I apply knowledge available in ECS to solve new problems" and "I effectively utilize knowledge in ECS into practical use".
4.2.4. Innovative behavior. Innovative behavior is measured by ten-items scale adapted from [18]. Sample included, "Always generate original solutions for problems using ECS" and "Always wonder how things can be improved using ECS".

4.2.5. ECS satisfaction. ECS satisfaction is measured using four-items scale adapted from [10, 54]. Sample items included, "How do you feel about your overall experience of ECS use" and "My interaction with ECS system is satisfying".

4.2.6. Job performance. Individual job performance is measured using three-items scale from [39]. Sample included, "ECS helps me to be more effective" and "ECS has a positive impact on my productivity in my job".

4.2.7. Control variables. To control for unknown effects, several control variables will be included because some evidence indicates that these demographic factors might be related to some contextual and dependent variable are included in the study. Four variables (i.e., age, education, gender, and experience) will be controlled because prior research has linked gender differences, age, job position, and education to work environment, and IS [47].

\subsection{Data analysis}

Partial least squares (PLS), as implemented in SmartPLS version 2.0, is used for data analysis [49]. The PLS approach allows researchers to assess measurement model parameters and structural path coefficients simultaneously [47]. PLS is used for several reasons: (1) this study was primarily intended for causal-predictive analysis; (2) PLS requires fewer statistical specifications and constraints on the data than the covariance-based strategy of LISREL (e.g., assumptions of normality); and (3) PLS is effective for those early-theory testing situations that characterized this study. Therefore, PLS is an appropriate statistical analysis tool for the current study. It focuses on a prediction-oriented and data-analytic method, seeking to maximize the variances that are explained in the constructs [8].

\subsection{Results}

4.4.1. Measurement model. PLS generates statistics to test the validity and reliability of latent constructs that include composite reliability (CR), 
average variance extracted (AVE), Cronbach's alpha (CA), intercorrelations among variables, and square root of AVE on the diagonal. First, by examination, all factor loadings of indicators associated with each construct are >0.6. Second, the CR, an internal consistency estimate similar to $\mathrm{CA}$, for each construct is > 0.7. Third, the AVE exceeded the recommended criterion of 0.5 for all measures [14, 22, 27, 59].

In PLS, convergent and discriminant validity is assessed using criteria that the construct representing items should share more variance with its items that with other constructs in the model [13]. The diagonal elements in the matrix in Table 2 shows the square root of the AVE by each construct with its indicators. Sufficient convergent and discriminant validity was obtained based on examination of the values.

4.4.2. Structural model. Figure 1 depicts the PLS results. The hypothesized paths from knowledge sharing (H1) and support for creative use of ECS (H2) have significant impact on knowledge application, supporting both. As expected, knowledge application has significant impact on ECS satisfaction (H3), and positive impact on innovative behavior (H4). ECS satisfaction has significant impact on job performance, supporting (H5). Innovative behavior also has positive impact on job performance (H6). The relationship between knowledge application and job performance is found to be not significant. None of the control variables has significant impact on job performance.

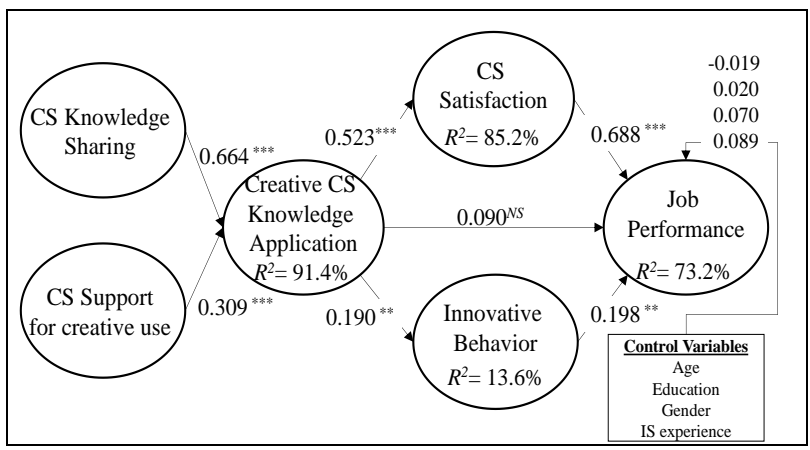

Figure 1. Analys is results

\subsection{Post-Hoc analysis}

The purpose of the post-hoc analysis is to further investigate the mediating effects of ECS satisfaction and innovative behavior on the relationship between KA and job performance. while the correlation results in Table 1 showed high relation between creative knowledge application with ECS and employees job performance, the result indicated no significant relationship that led us to further explore the roles of
ECS satisfaction and innovative behavior on the relationship. In the post hoc analysis, to test our mediation effect, we employed Baron and Kenny's mediation test [9]. Due to the multiple mediators (ECS satisfaction and innovative behavior), we investigated the effect of each respective mediator on the relationship. This way allowed us to explore a specific mediated path, which provided information on the unique effect of the respective mediator, while controlling for the other mediator [35].

We first, identified whether CKA was significantly related to job performance when the mediator is not added to job performance. The result showed a significant relationship $(\beta=0.766, \mathrm{p}<0.001)$. Next, the mediators and job performance were significantly related to each other as shown in Figure 2. Lastly, to infer a full/partial mediation effect, the direct relationship between the CKA and job performance should be nonsignificant.

Figure 2 shows the results of mediation analysis. When ECS satisfaction was added into the direct relationship, this variable was significantly related to job performance $(\beta=0.655, p<0.001)$. When innovative behavior was added into the direct relationship, this mediator had also significantly but relatively weak relationship with job performance $(\beta=$ $0.181, p<0.01)$.

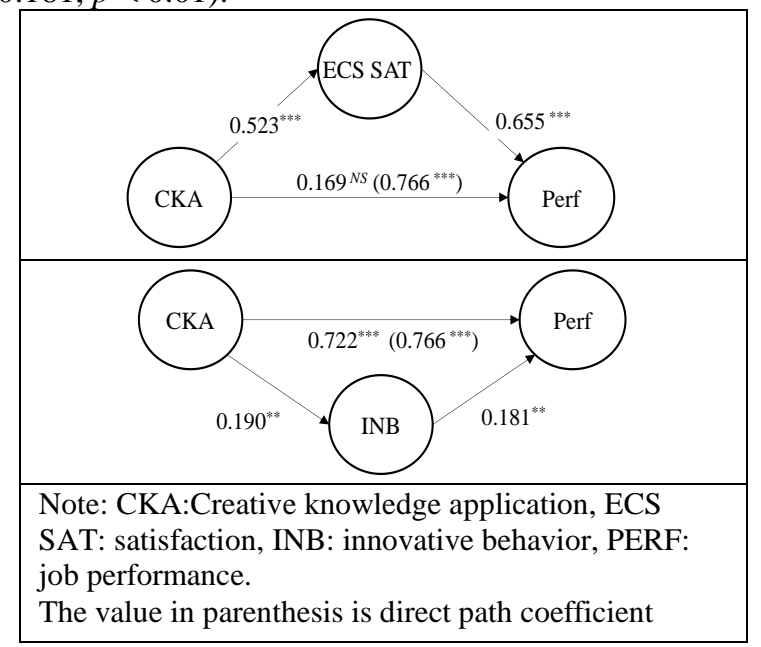

Figure 2. Mediating analys is results

Conversely, the direct effect of CKA to job performance $(\beta=0.766, p<0.01 \rightarrow \beta=0.169, p>$ $0.10)$ became non-significant for CS satisfaction, indicating the presence of the full mediation effect, while innovative behavior showed partial mediation effect $(\beta=0.766, p<0.01 \rightarrow \beta=0.722, p<0.001)$. The results of the post hoc analysis showed that ECS satisfaction is more important factor mediating the effect of CKA to job performance than innovative behavior does. The possible explanation could be the 
work environment where employees works with crowdsourcing systems and under this environment, employees highly likely consider satisfaction with crowdsourcing system as critical factor enhancing their job performance. That is, employees' creative using behavior of crowdsourcing system for applying knowledge in their work could be overlooked because ECS satisfaction absorbs the effect of it on job performance. This result provides additional insight into contributing factors to the social network adoption levels.

\section{Discussion and conclusion}

This study responds to the fundamental yet unanswered question of whether ECS factors such as knowledge sharing and support for creative use of ECS impact employees' use of ECS to actively submit and share their innovative ideas to improve their job performance. The findings show that two features of enterprise crowdsourcing systems lead employees creatively apply knowledge with ECS to do their work. Our finding that the technical feature (i.e., KS) and employees cognitive feature (i.e., CS support) have positive impact on CKA aligns with the findings and studies of [15] and [47] in transactive memory systems and virtual communities. The one of the findings also reveals the CKA with ECS increase employees' satisfaction on ECS and their innovative behavior. In addition, with the strong relationship between CKA and job performance, the post hoc findings showed that the effect of CKA on job performance are mediated by mainly ECS satisfaction, this result is consistent with past study [See, 48]. In addition, having a weaker relationship between CKA and innovative behavior is possible since all submitted ideas don't get implemented [7] for both financial and political reasons in organizations.

Enterprises can be satisfied that existing ECS factors help improving employees' job performance, but should find ways to improve innovative behavior. They can improve innovative behavior by first understanding employees' intrinsic and extrinsic motivational factors, reviewing current rewarding system and implementing solid rewarding systems [11]. Enterprises can show that executives support knowledge application, new product development [7], and acknowledge and provide social recognition for implementing innovative behavior [63]. Enterprises should continue using all ECS especially trust management to provide confidence to employees that an effective reward system is in place to reward their innovation.

This study is a preliminary step toward deep understanding of ECS factors impacting employee participation to participate and share innovative ideas. However, we are restricted to generalize our findings by studying a limited industry types. Future research will aim for statistical generalization by including samples from various industries including non-profit and government organizations across the globe.

Overall, the research profiled in this paper would contribute to understanding the relationship between ECS factors, and employees' job performance through innovative behavior in terms of knowledge application and ECS satisfaction in organizations using ECS for innovation. The results would call attention to how ECS factors influence employees' innovative behavior, and help organizations to fine tune their ECS to attract more employee participation. We hope that this study serves as encouragement for future research endeavors.

\section{References}

[1] M. K. Ahuja and J. B. Thatcher, "Moving beyond intentions and toward the theory of trying: effects of work environment and gender on post-adoption information technology use", MIS quarterly, 29 (2005), pp. 427-459.

[2] M. Alavi and D. E. Leidner, "Review: Knowledge management and knowledge management systems: Conceptual foundations and research issues", MIS quarterly (2001), pp. 107-136.

[3] T. M. Amabile, "A model of creativity and innovation in organizations", Research in organizational behavior, 10 (1988), pp. 123-167.

[4] N. Anderson, K. Potočnik and J. Zhou, "Innovation and creativity in organizations a state-of-the-science review, prospective commentary, and guiding framework", Journal of Management, 40 (2014), pp. 1297-1333.

[5] N. Anderson, K. Potočnik and J. Zhou, "Innovation and creativity in organizations: A state-of-the-science review, prospective commentary, and guiding framework", Journal of Management, 40 (2014), pp. 1297-1333.

[6] N. Au, E. W. Ngai and T. E. Cheng, "Extending the understanding of end user information systems satisfaction formation: An equitable needs fulfillment model approach", MIS quarterly (2008), pp. 43-66.

[7] M. Baer, "Putting creativity to work: The implementation of creative ideas in organizations", Academy of Management Journal (2012), pp. amj. 2009.0470.

[8] D. Barclay, C. Higgins and R. Thompson, "The partial least squares (PLS) approach to causal modeling: Personal computer adoption and use as an illustration", Technology studies, 2 (1995), pp. 285309. 
[9] R. M. Baron and D. A. Kenny, "The moderatormediator variable distinction in social psychological research: Conceptual, strategic, and statistical considerations", Journal of Personality and Social Psychology, 51 (1986), pp. 1173-1182.

[10] A. Bhattacherjee, "Understanding information systems continuance: an expectation-confirmation model", MIS quarterly (2001), pp. 351-370.

[11] U. Bretschneider, B. Rajagopalan and J. M. Leimeister, Idea generation in virtual communities for innovation: The influence of participants' motivation on idea quality, System Science (HICSS), 2012 45th Hawaii International Conference on, IEEE, 2012, pp. 3467-3479.

[12] C.-J. Chen and J.-W. Huang, "Strategic human resource practices and innovation performance-The mediating role of knowledge management capacity", Journal of business research, 62 (2009), pp. 104-114.

[13] W. W. Chin, Commentary: Issues and opinion on structural equation modeling, JSTOR, 1998.

[14] W. W. Chin, How to write up and report PLS analyses, Handbook of partial least squares, Springer, 2010, pp. 655-690.

[15] S. Y. Choi, H. Lee and Y. Yoo, "The impact of information technology and transactive memory systems on knowledge sharing, application, and team performance: a field study", MIS quarterly (2010), pp. 855-870.

[16] J. M. Conway and C. E. Lance, "What reviewers should expect from authors regarding common method bias in organizational research", Journal of Business and Psychology, 25 (2010), pp. 325-334.

[17] B. Dalton, "Creativity, habit, and the social products of creative action: Revising Joas, incorporating Bourdieu", Sociological Theory, 22 (2004), pp. 603-622.

[18] J. De Jong and D. Den Hartog, "Measuring innovative work behaviour", Creativity and Innovation Management, 19 (2010), pp. 23-36.

[19] W. H. Delone and E. R. McLean, "The DeLone and McLean model of information systems success: a ten-year update", Journal of management information systems, 19 (2003), pp. 9-30.

[20] W. H. DeLone and E. R. McLean, "Information systems success: The quest for the dependent variable", Information systems research, 3 (1992), pp. 60-95.

[21] J. Etezadi-Amoli and A. F. Farhoomand, "A structural model of end user computing satisfaction and user performance", Information \& management, 30 (1996), pp. 65-73.

[22] C. Fornell and D. F. Larcker, "Evaluating structural equation models with unobservable variables and measurement error", Journal of marketing research (1981), pp. 39-50.
[23] J. Gardner, How to Succeed at Crowdsourcing Innovation, 2015.

[24] R. M. Grant, "Toward a knowledge-based theory of the firm", Strategic management journal, 17 (1996), pp. 109-122.

[25] T. Grublješič and J. Jaklič, "Conceptualization of the business intelligence extended use model", Journal of Computer Information Systems, 55 (2015), pp. 7282.

[26] T. Guimaraes and M. Igbaria, "Client/server system success: Exploring the human side", Decision Sciences, 28 (1997), pp. 851-876.

[27] J. F. Hair, B. Babin and R. E. Anderson, Multivariate Data Analysis, Prentice Hall, Upper Saddle, NJ, 2009.

[28] L. Hetmank, "Components and Functions of Crowdsourcing Systems-A Systematic Literature Review", Wirtschaftsinformatik, 4 (2013).

[29] C.-K. Hou, "Examining the effect of user satisfaction on system usage and individual performance with business intelligence systems: An empirical study of Taiwan's electronics industry", International Journal of Information Management, 32 (2012), pp. 560-573.

[30] J.-W. Huang and Y.-H. Li, "The mediating effect of knowledge management on social interaction and innovation performance", International Journal of Manpower, 30 (2009), pp. 285-301.

[31] S. Im and J. P. Workman Jr, "Market orientation, creativity, and new product performance in hightechnology firms", Journal of marketing, 68 (2004), pp. 114-132.

[32] B. Ives, M. H. Olson and J. J. Baroudi, "The measurement of user information satisfaction", Communications of the ACM, 26 (1983), pp. 785-793. [33] O. Janssen, "How fairness perceptions make innovative behavior more or less stressful", Journal of Organizational Behavior, 25 (2004), pp. 201-215.

[34] L. Jarle Gressgård, O. Amundsen, T. Merethe Aasen and K. Hansen, "Use of information and communication technology to support employee-driven innovation in organizations: a knowledge management perspective", Journal of Knowledge Management, 18 (2014), pp. 633-650.

[35] D. A. Kenny, D. A. Kashy and N. Bolger, Data analysis in social psychology, in D. T. Gilbert, S. T. Fiske and G. Lindzey, eds., The handbook of social psychology Oxford University Press, New York, 1998, pp. 233-265.

[36] H. Kim and G. Yuk1, "Relationships of managerial effectiveness and advancement to self-reported and subordinate-reported leadership behaviors from the multiple-linkage mode", The leadership quarterly, 6 (1995), pp. 361-377. 
[37] R. Klein, A. Rai and D. W. Straub, "Competitive and cooperative positioning in supply chain logistics relationships", Decision Sciences, 38 (2007), pp. 611 646.

[38] J. Koh and Y.-G. Kim, "Knowledge sharing in virtual communities: an e-business perspective", Expert systems with applications, 26 (2004), pp. 155166.

[39] B. Kositanurit, K.-M. Osei-Bryson and O. Ngwenyama, "Re-examining information systems user performance: Using data mining to identify properties of IS that lead to highest levels of user performance", Expert Systems with Applications, 38 (2011), pp. 7041-7050.

[40] J. Laurin, POLARIS INDUSTRIES: DRIVING BREAKTHROUGH INNOVATION THROUGH CROWDSOURCING.

[41] P. M. Leonardi, "Social media, knowledge sharing, and innovation: Toward a theory of communication visibility", Information systems research, 25 (2014), pp. 796-816.

[42] X. Li, J. P.-A. Hsieh and A. Rai, "Motivational differences across post-acceptance information system usage behaviors: An investigation in the business intelligence systems context", Information systems research, 24 (2013), pp. 659-682.

[43] E. A. Locke, ed., The nature and causes of job satisfaction, Rand McNally, Chicago, 1976.

[44] N. P. Melone, "A theoretical assessment of the user-satisfaction construct in information systems research", Management science, 36 (1990), pp. 76-91.

[45] R. Ngah and A. R. Ibrahim, "The Influence of Intellectual Capital on Knowledge Sharing: Small and Medium Enterprises' Perspective", Communications of the IBIMA, 2011 (2011), pp. 1-13.

[46] I. Nonaka and H. Takeuchi, The knowledgecreating company: How Japanese companies create the dynamics of innovation, Oxford university press, 1995.

[47] I. Park, M. Al-Ramahi and J. Cho, "The Effect of Perceived IS Support for Creativity on Job Satisfaction: The Role of effective IS use in virtual workplaces", (2015).

[48] S. Petter, W. DeLone and E. McLean, "Measuring information systems success: models, dimensions, measures, and interrelationships", European journal of information systems, 17 (2008), pp. 236-263.

[49] C. M. Ringle, S. Wende and A. Will, SmartPLS 2.0 (beta), Hamburg, 2005.

[50] G. D. Saxton, O. Oh and R. Kishore, "Rules of crowdsourcing: Models, issues, and systems of control", Information Systems Management, 30 (2013), pp. 2-20.

[51] T. A. Scandura and C. A. Schriesheim, "Leadermember exchange and supervisor career mentoring as complementary constructs in leadership research", Academy of management Journal, 37 (1994), pp. 15881602.

[52] S. G. Scott and R. A. Bruce, "Determinants of innovative behavior: A path model of individual innovation in the workplace", Academy of management journal, 37 (1994), pp. 580-607.

[53] C. E. Seidel, B. E. Thapa, R. Plattfaut and B. Niehaves, Selective crowdsourcing for open process innovation in the public sector: are expert citizens really willing to participate?, Proceedings of the 7th International Conference on Theory and Practice of Electronic Governance, ACM, 2013, pp. 64-72.

[54] M. M. Sharabati, A. Sulaiman and N. A. M. Salleh, "End User Satisfaction and Individual Performance Assessments in e-Procurement Systems", International Journal of Computer Theory and Engineering, 7 (2015), pp. 503.

[55] P. M. S. Smith, P. Kesting and J. P. Ulhųi, What are the driving forces of employee driven innovation?, 9th International CINet Conference, 2008.

[56] V. Sood, Crowdsourcing: IT companies engage with staff to get innovative ideas, lift morale, The Economic Times, 2014.

[57] I. Svetlik, E. Stavrou-Costea and H.-F. Lin, "Knowledge sharing and firm innovation capability: an empirical study", International Journal of manpower, 28 (2007), pp. 315-332.

[58] S. H. Thomke, Experimentation matters: unlocking the potential of new technologies for innovation, Harvard Business Press, 2003.

[59] V. E. Vinzi, L. Trinchera and S. Amato, PLS path modeling: from foundations to recent developments and open issues for model assessment and improvement, Handbook of partial least squares, Springer, 2010, pp. 47-82.

[60] C. Viswesvaran and D. S. Ones, "Perspectives on models of job performance", International Journal of Selection and Assessment, 8 (2000), pp. 216-226.

[61] A. Wendelken, F. Danzinger, C. Rau and K. Moeslein, "Innovation without me : why employees do (not) participate in organizational innovation communities", R \& D management, 44 (2014), pp. 217-236.

[62] D. Youden, J. Lee and J. Angsuwat, Harnessing the power of crowdsourcing: Does your company stand out in a crowd?, PwC, 2011.

[63] F. Yuan and R. W. Woodman, "Innovative behavior in the workplace: The role of performance and image outcome expectations", Academy of Management Journal, 53 (2010), pp. 323-342.

[64] J. Zhou and J. M. George, "When job dissatisfaction leads to creativity: Encouraging the expression of voice", Academy of Management journal, 44 (2001), pp. 682-696. 
[65] M. Zviran and Z. Erlich, "Measuring IS user satisfaction: review and implications", Communications of the Association for Information Systems, 12 (2003), pp. 5. 